\title{
Notiz betreffend die Sichtbarkeitsverhältnisse des grossen September-Cometen.
}

Die Elemente des Herrn Dr. Oppenheim in Nr. 2459 der A. N. stellen den Lauf des Cometen ziemlich genau dar, denn meine Beobachtung vom 8. Oct. giebt die Correction der Ephemeride $=-18^{s}$ und $+0^{\prime} \mathbf{2}$. Es schien mir interessant, besonders nachdem in Athen ein neuer Comet, in derselben Gegend des Himmels und in gleicher Weise sich bewegend, entdeckt worden ist, zu prüfen; wie sich der grosse Comet vor dem Perihel und um die Zeit des Perihels bewegt hat. Herr Dr. Lamp hat zu diesem Behufe folgende Ephemeride nach Dr. Oppenheim's Elementen berechnet:

Mittl. Berl. Mitt a g.

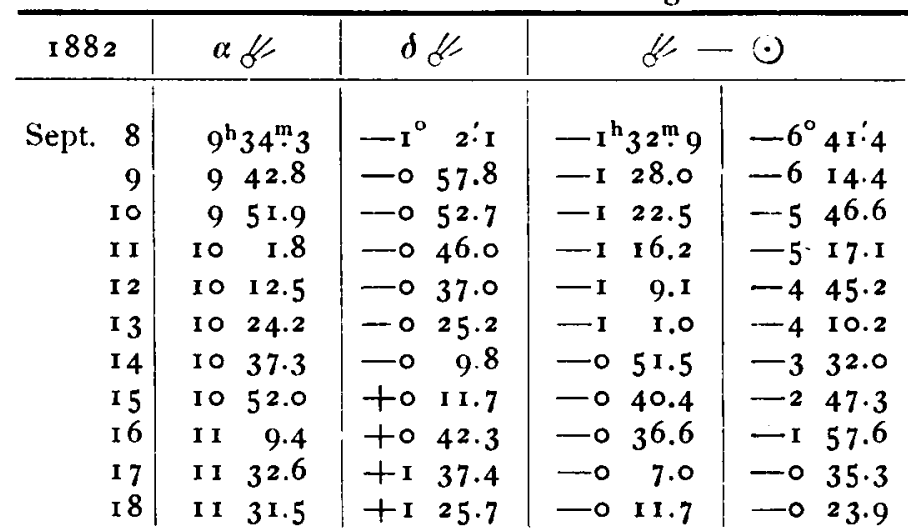

Die Beobachtung vom 8. Sept. am Cap (A. N. 2462) giebt folgende Unterschiede: B-R $=-0^{\mathrm{m}} \cdot \mathbf{2}$ und $+13^{\prime} 7^{*}$ ) und gehört somit zu dem Cometen. Dagegen lässt sich die Beobachtung in Rio Janeiro (A. N. 2456) zunächst nicht mit obiger Rechnung vereinigen.

Für die Zeit des Perihels, die schon ziemlich sicher fixirt zu sein scheint, habe ich in engeren Intervallen folgende Oerter nach denselben Elementen eingeschaltet:

\begin{tabular}{|c|c|c|c|c|c|c|c|}
\hline " $\&$ & M. Z. Berlin & $\alpha \not y$ & $d \&$ & \multicolumn{2}{|c|}{$b^{\prime}-\odot$} & $\log \Delta \not 4$ & $\log R \odot$ \\
\hline$-90^{\circ}$ & Sept. 17.1961 & $11^{\mathrm{h}} 39^{\mathrm{m}} \cdot 5$ & $+2^{\circ} 0^{\prime} \cdot 4$ & $-0^{m} 8$ & $-0^{\circ} 7^{\prime} \cdot 7$ & 9.99553 & 0.00191 \\
\hline-60 & .2338 & I I 4 I. I & +26.8 & +0.7 & -00.5 & 9.99772 & 0.00196 \\
\hline-30 & .2537 & I 1411.8 & +210.2 & +1.3 & to 3.3 & 9.99949 & 0.00189 \\
\hline$\circ$ & .2686 & I 42.1 & +212.6 & $+1: 5$ & to 6.1 & 0.00166 & 0.00189 \\
\hline+30 & .2835 & 1142.3 & +2 I 3.7 & +1.7 & to 7.6 & 0.00291 & 0.00188 \\
\hline+60 & .3035 & I I 42.1 & +2 I 4.0 & +1.4 & to 8.3 & 0.00506 & 0.00188 \\
\hline+90 & .3411 & I I $4 \times .5$ & +2 I 3.0 & +0.7 & to 8.2 & 0.00723 & 0.00187 \\
\hline+120 & .4570 & I I 39.2 & +2 & -2.0 & to 2.3 & $0.0143^{2}$ & 0.00185 \\
\hline
\end{tabular}

$\mathrm{H}_{\mathrm{i}}$ ernach muss der Schweif des Cometen eine kırze Zeit lang nach Nordosten gerichtet gewesen sein (Pos. W. zwischen $0^{\circ}$ und $90^{\circ}$ ), und damit würde die in A. N. Nr. 2459 mitgetheilte Beobachtung in Bien hoa in sofern eine Erklärung finden, als am 17 . Sept., um $16 \frac{1}{2}$ Uhr Localzeit etwa, unter dortiger Länge der Schweif des Cometen, aber nicht der Kopf desselben, am Morgenhimmel sichtbar gewesen wäre.

Kiel 1882 Oct. I 2.

A. Krueger.

*) In $\mathrm{Nr} .676$ der, Nature wird die Declination von Sept. 8 in $-0^{\circ} 6^{\prime}{ }_{3} 0^{\prime \prime}$ verbessert; danach stellt sich die Correction der Elemente $\mathrm{zu}-\mathrm{o}_{\mathbf{m}}^{\mathrm{m}}$ und $+2 \cdot 7^{\circ}$ An derselben Stelle wird die merkwürdige Beobachtung mitgetheilt, dass der Comet Sept. 17 um $4^{\mathrm{h}} 50^{\mathrm{m}} 5^{\mathrm{s}}$ M. Z. Cap plötzlich beim Eintritt in die Sonnenscheibe verschwunden und auf der Sonne nicht sichtbar gewesen se:.

\section{In halt:}

Zu Nr. 2460-6r. Chas. H. Kummell. On the composition of errors from single causes of error. 177. - F. Terby. Observation de la comete Cruls à Louvain le 2 Octobre. 205. - C.F.W. Peters. Beobachtungen des Cometen Cruls am Aequatoreal der Kieler Sternwarte. 205. - A. Krueger. Notiz betreffend die Sichtbarkeitsverhältnisse des grossen September-Cometen. 207. 